\title{
ANALISA PENGARUH KUALITAS SINKAD DAN LAYANAN TERHADAP KEPUASAN MAHASISWA LEMBAGA PENDIDIKAN WEARNES EDUCATION CENTER MALANG
}

\author{
Yuniar Fitriyani*, Fathorrahman, Theresia Pradiani \\ PPS STIE ASIA, Sekolah Tinggi IImu Ekonomi Asia Malang, Sekolah Tinggi IImu Ekonomi Asia Malang
}

INFO ARTIKEL

DOI: 10.32812/jibeka.v13i2.119

ISSN-P: 0126-1258

ISSN-E: 2620-875X

Keywords: Information quality, system quality, academic services, non-academic services, student satisfaction
Kata Kunci: Kualitas informasi, kualitas sistem, layanan akademik, layanan non-akademik, kepuasan mahasiswa

\section{ABSTRACT}

This research intends to analyze student satisfaction that is influenced by the quality of information and the SINKAD system, academic and non-academic services where the research was conducted at the Malang Wearnes Education Center Education Institute.This research used a non-probability sampling approach with purposive sampling "sampling technique". The research used questionnaires as an instrument which was conducted to 90 respondents of Wearnes Education Center Malang regular students Academic Year 2017-2018 who were active in college in the process of preparing the On The Job Training report when distributing questionnaires. The research data is processed quantitatively with multiple linear regression analysis techniques using SPSS 25.0. Results of the research are supported by qualitative data used to strengthen the results of the research. The results of this research showed that: (1) The relevance of the information presented by SINKAD has an influence on student satisfaction at Wearnes Education Center Malang (2) the quality of the SINKAD system does not have an influence on student satisfaction at Wearnes Education Center Malang (3) Reliability of academic services has an influence on student satisfaction at Wearnes Education Center Malang (4) Reliability of non-academic services has an influence on student satisfaction in Wearnes Education Center Malang (5) Information quality of SINKAD, quality of SINKAD system, quality of academic services and non-academic service quality together have an influence on satisfaction college student.

\section{ABSTRAK}

Penelitian ini bermaksud untuk menganalisis kepuasan mahasiswa yang dipengaruhi oleh kualitas informasi dan sistem SINKAD, layanan akademik dan non-akademik yang dilaksanakan pada Lembaga Pendidikan Wearnes Education Center Malang. Penelitian ini menggunakan pendekatan non-probability sampling dengan teknik pengambilan sampel purposive sampling. Instrumen penelitian menggunakan kuesioner pada 90 responden mahasiswa jalur regular Tahun Akademik 2017-2018 Wearnes Education Center Malang yang berstatus aktif kuliah dalam proses penyusunan laporan On The Job Training saat penyebaran kuesioner. Data penelitian diolah secara kuantitatif dengan Teknik Analisa regresi linear berganda menggunakan SPSS 25.0. Hasil penelitian didukung data kualitatif yang digunakan untuk menguatkan hasil penelitian. Hasil penelitian ini menunjukkan bahwa : (1) Relevansi informasi yang disajikan oleh SINKAD mempunyai pengaruh terhadap kepuasan mahasiswa di Wearnes Education Center Malang (2) Kualitas sistem SINKAD tidak mempunyai pengaruh terhadap kepuasan mahasiswa di Wearnes Education Center Malang (3) Keandalan layanan akademik mempunyai pengaruh terhadap kepuasan mahasiswa di Wearnes Education Center Malang (4) Keandalan layanan non-akademik mempunyai pengaruh terhadap kepuasan mahasiswa di Wearnes Education Center Malang (5) Kualitas informasi SINKAD, kualitas sistem SINKAD, kualitas layanan akademik dan kualitas layanan non-akademik secara bersama-sama mempunyai pengaruh terhadap kepuasan mahasiswa. 


\section{Pendahuluan}

Perubahan kondisi sosial masyarakat yang semakin meningkat menyebabkan masyarakat semakin sadar akan kualitas dan menimbulkan kecenderungan untuk menuntut pelayanan yang lebih cepat dan lebih baik agar kebutuhannya terpenuhi serta merasa puas atas pelayanan yang diterimanya. Lembaga pendidikan sebagai penyedia layanan pendidikan memegang peranan penting dalam melanjutkan peningkatan kualitas calon SDM setelah menjalani pendidikan tingkat SD, SMP dan SMU, akan tetapi masih banyak ditemukan adanya ketidaksesuaian kualitas layanan dan fasilitas yang diberikan oleh SDM di dalamnya. Wearnes Education Center Malang sebagai lembaga pendidikan program 1 tahun harus mampu memberikan fasilitas dan SDM yang mampu melayani dengan baik kepada mahasiswa karena institusi dan SDM yang dipekerjakan di dalamnya memperoleh kesejahteraan hidup berasal dari kantong-kantong mahasiswa. Sudah selayaknya semua unsur yang terlibat dalam menjalankan kegiatan operasional suatu lembaga pendidikan memberikan layanan yang baik sesuai dengan harapan mahasiswa agar merasa senang sehingga timbul kepuasan.

Kotler dan Keller (2012:150), "satisfaction is a person's feelings of pleasure or disapointment that result from comparing a product's perceived performance or utcome) to expectations. (Kepuasan konsumen adalah perasaan senang atau kecewa seseorang yang muncul setelah membandingkan kinerja /hasil produk yang dipikirkan terhadap kinerja yang diharapkan)". Bila kinerja telah memenuhi atau melebihi harapan, mahasiswa akan merasa puas tetapi sebaliknya bila kinerja tidak sesuai harapan akan kecewa. Konsumen yang sangat puas akan menyebarkan cerita positif dari mulut ke mulut tentang pengalaman manisnya selama studi dan malah akan menjadi iklan serta dapat menimbulkan minat merekomendasikan kepada orang lain agar menempuh studi di Wearnes Education Center Malang . Sebaliknya, konsumen yang tidak puas cenderung akan bereaksi dengan tindakan yang sangat berbeda atas layanan yang diterima. Ada yang diam saja, ada juga yang melakukan protes /complain. Sing, J (1988), yang mengemukakan terdapat 3 kategori tanggapan terhadap ketidakpuasan konsumen : Voice response (keluhan disampaikan langsung kepada perusahaan), Private response (keluhan disampaikan kepada kolega,teman), Third-party response (keluhan disampaikan lewat media massa). Ketidakpuasan ini dikuatirkan akan terus dapat menurunkan jumlah perolehan mahasiswa, terbukti dalam 5 tahun jumlah perolehan mahasiswa semakin menurun.

Penerapan teknologi informasi memainkan peranan yang penting dalam memberikan layanan, salah satunya adalah penerapan Sistem Informasi Akademik (SINKAD) untuk meminimalkan kekeliruan dan ketidakkelengkapan data akademik. Penelitian Ismatullah (2014:36), SINKAD dapat membantu dalam mengolah data dan melakukan proses kegiatan akademik yang melibatkan antara mahasiswa, dosen, administrasi akademik, keuangan dan data atribut lainnya. Sedangkan penelitian DeLone dan McLean (1992) menemukan faktor yang mempengaruhi kepuasan pengguna sebuah sistem informasi adalah kualitas informasi dan kualitas sistem.

Ditinjau dari kualitas informasinya, DeLone dan Mclean (1992) mengemukakan kualitas informasi merupakan kualitas kemampuan konten dalam memberikan informasi yang disajikan apakah benar-benar dapat membantu mencari informasi yang dibutuhkan oleh penggunanya. Kriteria yang dapat digunakan untuk menilai kualitas informasi antara lain : relevance, accurate, timeliness, dan reliability. Usaha menyajikan informasi yang 
akurat, lengkap dan tepat waktu telah dilakukan oleh Wearnes Education Center Malang meliputi kemampuan konten SINKAD dalam memberikan informasi yang dapat diandalkan, selalu meng-up to date informasi portal SINKAD karena dikuatirkan turut andil dalam mempengaruhi kepuasan mahasiswa. Beberapa penelitian yang telah dilakukan sebelumnya mendukung pernyataan diatas, yaitu penelitian Swaryana et.al (2016) dan Zeinab (2016) bahwa kualitas informasi berpengaruh terhadap kepuasan pengguna. Namun penelitian Oktavia (2016) yang bertujuan menganalisis faktor-faktor yang mempengaruhi kesuksesan Sistem Informasi Manajemen Daerah (SIMDA) SKPD Palangkaraya dengan pendekatan model DeLone dan McLean menolak hasil hasil penelitian tersebut dan menemukan bahwa kualitas informasi tidak berpengaruh terhadap kepuasan pengguna Sistem Informasi Manajemen pada SKPD kota Palangkaraya.

Ditinjau dari kualitas sistem, DeLone dan McLean (1992) mengemukakan kualitas sistem merupakan kualitas kemampuan sistem perangkat lunak yang digunakan dalam sistem informasi apakah benar-benar dapat membantu penggunanya saat mengoperasikan sistem tersebut. Kriteria yang dapat digunakan untuk menilai kualitas sistem antara lain : ease of use, response time, reliability, flexibility, security. Upaya peningkatan kualitas performance hardware dan software SINKAD yang telah dilakukan Wearnes Education Center Malang meliputi kemudahan dalam penggunaan/user-friendly, kemudahan akses, ketersediaan sistem security data dan response time perlu ditelaah lebih lanjut karena dikuatirkan ikut andil dalam mempengaruhi kepuasan mahasiswa. Beberapa penelitian yang mendukung pernyataan diatas, yaitu Swaryana (2016), Zeinab (2016), MTebe (2018), Oktavia (2016) bahwa kualitas sistem berpengaruh terhadap kepuasan pengguna.

Layanan disediakan oleh SDM Wearnes Education Center Malang meliputi hal-hal yang bersifat akademik (tenaga akademik) dan juga bidang non-akademik (tenaga nonakademik) yang harus bersinergi dalam memberikan layanan agar tercapai apa yang diharapkan mahasiswa yaitu terlayani kebutuhannya sampai lulus tepat pada waktunya. Moenir (2001:27) melalui pendekatan model SERVQUAL (Service Quality) yang dikembangkan oleh Parasuraman, Zeithaml, dan Berry (1991) terdapat lima dimensi SERVQUAL yang dapat mempengaruhi kepuasan konsumen yaitu tangible (bukti fisik), reliability (kehandalan), responsiveness (tanggapan), assurance (jaminan), empathy (perhatian tulus).

Upaya peningkatan kualitas layanan akademik meliputi segala aktivitas yang berkaitan langsung dengan kegiatan belajar mengajar yang disediakan oleh tenaga akademik (dosen dan asisten dosen) memberikan pengajaran, keramahan tenaga akademik, tanggap dalam merespon kebutuhan akademik mahasiswa, kemampuan mengoperasikan media ajar, progress report hasil belajar kepada orang tua, peralatan dan teknologi yang digunakan dalam perkuliahan, ketelitian dosen dalam menilai studi mahasiswa, dan kebersihan ruangan perkuliahan dikuatirkan ikut berperan dalam mempengaruhi kepuasan mahasiswa.

Upaya peningkatan kualitas layanan non-akademik meliputi aktivitas layanan yang tidak berkaitan langsung dengan kegiatan belajar mengajar yang dalam pelaksanaannya disediakan oleh tenaga non akademik (front office, satpam, dan umum), yaitu keramahan dalam memberi layanan, tanggap dalam merespon kebutuhan non akademik, kerapian dalam berpenampilan, ketersediaan fasilitas tempat beribadah / musholla dan kamar mandi, kenyamanan ruang parkir, kebersihan lingkungan kampus, dan ketelitian petugas non akademik dalam menjalankan tugasnya dikuatirkan ikut berperan dalam mempengaruhi kepuasan mahasiswa. Hal tersebut tampak dari temuan penelitian sebelumnya Mulyawan 
(2016), Ali (2016), MTebe (2018) yang menyatakan bahwa kualitas layanan berpengaruh terhadap kepuasan. Namun temuan dalam penelitian tersebut ditolak oleh hasil penelitian Kitapci (2016) dan Jenniver (2016). Penelitian Kitapci (2016) bertujuan meneliti pengaruh dimensi kualitas layanan pada kepuasan pasien sebuah industri perawatan kesehatan di Turki. Hasilnya menyatakan bahwa dari 5 dimensi teori kualitas layanan Parasuraman et.al (1991), yang berpengaruh terhadap kepuasan hanyalah 3 dimensi saja yaitu assurance, empathy dan responsiveness, sedangkan tangible dan reliability tidak berpengaruh terhadap kepuasan pasien industri perawatan kesehatan di Turki. Sedangkan penelitian Jenniver (2016) bertujuan mengidentifikasi pengaruh kualitas layanan akademik Prodi Administrasi Bisnis terhadap kepuasan mahasiswa di Universitas Telkom Bandung. Hasilnya menemukan bahwa dari 5 dimensi kualitas layanan Parasuraman et.al (1991), yang berpengaruh terhadap kepuasan hanyalah 2 dimensi saja yaitu tangible dan responsiveness. Sedangkan reliability, assurance, empathy tidak berpengaruh terhadap kepuasan mahasiswa di Universitas Telkom Bandung.

\section{Metode Penelitian}

Lokasi penelitian dilaksanakan di Wearnes Education Center Malang selama 4 bulan terhitung mulai bulan Juni sampai dengan September 2018. Untuk menentukan jumlah sampel penelitian, digunakan teknik pengambilan sampel dengan menggunakan rumus Slovin dengan margin of error maximal sebesar $10 \%$. Populasi dari penelitian ini sudah diketahui secara pasti dan bersifat homogen sejumlah 699 mahasiswa reguler, sehingga metode pengambilan sampel berdasarkan probability sampling. Teknik pengambilan sampel adalah proportional random sampling Arikunto(2006) dengan jumlah sample 90 mahasiswa reguler yang tersebar di 5 jurusan.

Metode penelitian yang digunakan adalah kuantitatif karena menekankan analisanya pada data-data numerical (angka) yang diolah dengan metode statistik regresi linear berganda. Sebelum dilakukan penghitungan regresi linear berganda, terlebih dahulu dilakukan uji kualitas data/instrumen melalui uji validitas dan reliabilitas. Selanjutnya pengujian hipotesis (inferensial) yang diajukan menggunakan uji $t$ dan uji $F$ untuk mengetahui signifikansi hubungan variabel, serta dilengkapi juga uji determinasi agar diketahui seberapa besar kontribusi kualitas SINKAD (terdiri kualitas informasi dan kualitas sistem) dan kualitas layanan (terdiri layanan akademik dan non-akademik) terhadap kepuasan mahasiswa.

Hasil uji kualitas data menunjukkan seluruh instrument dalam penelitian ini dinyatakan valid dan reliabel sehingga dapat digunakan untuk penelitian lebih lanjut, dengan acuan nilai validitas $>0,1$ dan reliabilitas $>0,6$ yang disajikan sebagai berikut :

Tabel 1. Hasil Uji Validitas

\begin{tabular}{|c|c|c|c|c|}
\hline Variabel & Indikator & Item & Koefisien & Keterangan \\
\hline \multirow{12}{*}{$\begin{array}{c}\text { X1 } \\
\text { Kualitas } \\
\text { Informasi } \\
\text { SINKAD }\end{array}$} & \multirow{3}{*}{$\begin{array}{c}\mathrm{X} 1.1 \\
\text { Relevance }\end{array}$} & $\times 1.1 .1$ & 0.640 & Valid \\
\hline & & $x 1.1 .2$ & 0.638 & Valid \\
\hline & & $\mathrm{x} 1.1 .3$ & 0.623 & Valid \\
\hline & \multirow{3}{*}{$\begin{array}{c}\mathrm{X} 1.2 \\
\text { Accurate }\end{array}$} & x1.2.1 & 0.562 & Valid \\
\hline & & $\times 1.2 .2$ & 0.540 & Valid \\
\hline & & $\times 1.2 .3$ & 0.626 & Valid \\
\hline & \multirow{3}{*}{$\begin{array}{c}\mathrm{X} 1.3 \\
\text { Timeliness }\end{array}$} & $\mathrm{x} 1.3 .1$ & 0.558 & Valid \\
\hline & & $\mathrm{x} 1.3 .2$ & 0.366 & Valid \\
\hline & & $x 1.3 .3$ & 0.651 & Valid \\
\hline & \multirow{3}{*}{$\begin{array}{c}\text { X4 } \\
\text { Reliability }\end{array}$} & $x 1.4 .1$ & 0.679 & Valid \\
\hline & & $\mathrm{x} 1.4 .2$ & 0.603 & Valid \\
\hline & & $\times 1.4 .3$ & 0.593 & Valid \\
\hline \multirow{2}{*}{ 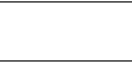 } & \multirow{2}{*}{$\begin{array}{c}\text { X2.1 } \\
\text { Ease of Use }\end{array}$} & $x 2.1 .1$ & 0.617 & Valid \\
\hline & & $x 2.1 .2$ & 0.809 & Valid \\
\hline
\end{tabular}

\begin{tabular}{|c|c|c|c|c|}
\hline \multirow{15}{*}{$\begin{array}{c}\text { X2 } \\
\text { Kualitas } \\
\text { Sistem } \\
\text { SINKAD }\end{array}$} & & $x 2.1 .3$ & 0.568 & Valid \\
\hline & & $\times 2.1 .4$ & 0.634 & Valid \\
\hline & \multirow{3}{*}{$\begin{array}{c}\mathrm{X} 2.2 \\
\text { Response } \\
\text { Time }\end{array}$} & $x 2.2 .1$ & 0.519 & Valid \\
\hline & & $x 2.2 .2$ & 0.596 & Valid \\
\hline & & $x 2.2 .3$ & 0.548 & Valid \\
\hline & \multirow{3}{*}{$\begin{array}{c}\mathrm{X} 2.3 \\
\text { Reliability }\end{array}$} & $x 2.3 .1$ & 0.337 & Valid \\
\hline & & $\times 2.3 .2$ & 0.322 & Valid \\
\hline & & $\times 2.3 .3$ & 0.547 & Valid \\
\hline & \multirow{3}{*}{$\begin{array}{c}\mathrm{X} 2.4 \\
\text { Flexible }\end{array}$} & $x 2.4 .1$ & 0.599 & Valid \\
\hline & & $x 2.4 .2$ & 0.519 & Valid \\
\hline & & $\times 2.4 .3$ & 0.526 & Valid \\
\hline & \multirow{4}{*}{$\begin{array}{c}\mathrm{X} 2.5 \\
\text { Security }\end{array}$} & $\times 2.5 .1$ & 0.586 & Valid \\
\hline & & $x 2.5 .2$ & 0.646 & Valid \\
\hline & & $\times 2.5 .3$ & 0.566 & Valid \\
\hline & & $x 2.5 .4$ & 0.425 & Valid \\
\hline
\end{tabular}




\begin{tabular}{|c|c|c|c|c|}
\hline \multirow{15}{*}{$\begin{array}{c}\text { X3 } \\
\text { Kualitas } \\
\text { Layanan } \\
\text { Akademik }\end{array}$} & \multirow{5}{*}{$\begin{array}{c}\text { X3.1 } \\
\text { Tangible }\end{array}$} & x3.1.1 & 0.624 & Valid \\
\hline & & $\times 3.1 .2$ & 0.400 & Valid \\
\hline & & $\times 3.1 .3$ & 0.639 & Valid \\
\hline & & $\times 3.1 .4$ & 0.681 & Valid \\
\hline & & $\times 3.1 .5$ & 0.686 & Valid \\
\hline & \multirow{4}{*}{$\begin{array}{c}\mathrm{X} 3.2 \\
\text { Responsive } \\
\text { ness }\end{array}$} & $\times 3.2 .1$ & 0.638 & Valid \\
\hline & & x3.2.2 & 0.646 & Valid \\
\hline & & x3.2.3 & 0.630 & Valid \\
\hline & & x3.2.4 & 0.649 & Valid \\
\hline & \multirow{6}{*}{$\begin{array}{c}\text { X3.3 } \\
\text { Empathy }\end{array}$} & x3.3.1 & 0.733 & Valid \\
\hline & & $\times 3.3 .2$ & 0.632 & Valid \\
\hline & & x3.3.3 & 0.663 & Valid \\
\hline & & x3.3.4 & 0.749 & Valid \\
\hline & & $\times 3.3 .5$ & 0.620 & Valid \\
\hline & & x3.3.6 & 0.690 & Valid \\
\hline & \multirow{5}{*}{$\begin{array}{c}\text { X3.4 } \\
\text { Reliability }\end{array}$} & $\times 3.4 .1$ & 0.349 & Valid \\
\hline & & x3.4.2 & 0.671 & Valid \\
\hline & & $\times 3.4 .3$ & 0.677 & Valid \\
\hline & & x3.4.4 & 0.576 & Valid \\
\hline & & $\times 3.4 .5$ & 0.724 & Valid \\
\hline & \multirow{4}{*}{$\begin{array}{c}\mathrm{X} 3.5 \\
\text { Assurance }\end{array}$} & x3.5.1 & 0.529 & Valid \\
\hline & & $x 3.5 .2$ & 0.602 & Valid \\
\hline & & $\times 3.5 .3$ & 0.667 & Valid \\
\hline & & $\times 3.5 .4$ & 0.656 & Valid \\
\hline & \multirow{5}{*}{$\begin{array}{c}\text { X4.1 } \\
\text { Tangible }\end{array}$} & $\times 4.1 .1$ & 0.273 & Valid \\
\hline & & $x 4.1 .2$ & 0.355 & Valid \\
\hline & & $\times 4.1 .3$ & 0.300 & Valid \\
\hline & & $\times 4.1 .4$ & 0.475 & Valid \\
\hline & & $\times 4.1 .5$ & 0.498 & Valid \\
\hline
\end{tabular}

\begin{tabular}{|c|c|c|c|c|}
\hline \multirow{18}{*}{$\begin{array}{c}\text { X4 } \\
\text { Kualitas } \\
\text { Layanan } \\
\text { Non- } \\
\text { Akademik }\end{array}$} & \multirow{6}{*}{$\begin{array}{c}\mathrm{X} 4.2 \\
\text { Responsive } \\
\text { ness }\end{array}$} & $x 4.2 .1$ & 0.609 & Valid \\
\hline & & $\times 4.2 .2$ & 0.465 & Valid \\
\hline & & $\times 4.2 .3$ & 0.598 & Valid \\
\hline & & $\times 4.2 .4$ & 0.621 & Valid \\
\hline & & $\times 4.2 .5$ & 0.666 & Valid \\
\hline & & $\times 4.2 .6$ & 0.661 & Valid \\
\hline & \multirow{4}{*}{$\begin{array}{c}\text { X4.3 } \\
\text { Empathy }\end{array}$} & $x 4.3 .1$ & 0.625 & Valid \\
\hline & & $\times 4.3 .2$ & 0.440 & Valid \\
\hline & & $x 4.3 .3$ & 0.633 & Valid \\
\hline & & $\times 4.3 .4$ & 0.452 & Valid \\
\hline & \multirow{5}{*}{$\begin{array}{c}\mathrm{X} 4.4 \\
\text { Reliability }\end{array}$} & $x 4.4 .1$ & 0.762 & Valid \\
\hline & & $\times 4.4 .2$ & 0.678 & Valid \\
\hline & & $x 4.4 .3$ & 0.643 & Valid \\
\hline & & $\times 4.4 .4$ & 0.626 & Valid \\
\hline & & $\times 4.4 .5$ & 0.707 & Valid \\
\hline & \multirow{3}{*}{$\begin{array}{c}\text { X4.5 } \\
\text { Assurance }\end{array}$} & $\times 4.5 .1$ & 0.680 & Valid \\
\hline & & $x 4.5 .2$ & 0.420 & Valid \\
\hline & & $\times 4.5 .3$ & 0.726 & Valid \\
\hline \multirow{10}{*}{$\begin{array}{c}\text { Y } \\
\text { Kepuasan }\end{array}$} & \multirow{5}{*}{$\begin{array}{c}\text { Y1.1 } \\
\text { Kesesuaian } \\
\text { Harapan }\end{array}$} & $\mathrm{y} 1.1 .1$ & 0.734 & Valid \\
\hline & & y1.1.2 & 0.767 & Valid \\
\hline & & y1.1.3 & 0.686 & Valid \\
\hline & & y1.1.4 & 0.632 & Valid \\
\hline & & y1.1.5 & 0.531 & Valid \\
\hline & \multirow{5}{*}{$\begin{array}{c}\text { Y1.2 } \\
\text { Kesediaan } \\
\text { Merekomen } \\
\text { dasi }\end{array}$} & y1.2.1 & 0.726 & Valid \\
\hline & & y1.2.2 & 0.773 & Valid \\
\hline & & y1.2.3 & 0.770 & Valid \\
\hline & & y1.2.4 & 0.557 & Valid \\
\hline & & y1.2.5 & 0.657 & Valid \\
\hline
\end{tabular}

Tabel 2. Hasil Uji Reabilitas

\begin{tabular}{|c|c|c|c|c|c|}
\hline & $\begin{array}{c}\text { Scale Mean if Item } \\
\text { Deleted }\end{array}$ & $\begin{array}{l}\text { Scale Variance if } \\
\text { Item Deleted }\end{array}$ & $\begin{array}{l}\text { Corrected Item- } \\
\text { Total Correlation }\end{array}$ & $\begin{array}{l}\text { Cronbach's Alpha } \\
\text { if Item Deleted }\end{array}$ & Keterangan \\
\hline Kualitas Informasi SINKAD(X1) & 286.92 & 581.825 & .620 & .782 & Reliabel \\
\hline Kualitas Sistem SINKAD(X2) & 267.32 & 515.704 & .694 & .751 & Reliabel \\
\hline Kualitas Layanan Akademik(X3) & 232.00 & 410.067 & .633 & .780 & Reliabel \\
\hline Kualitas Layanan Non Akademik(X4) & 255.40 & 443.142 & .573 & .797 & Reliabel \\
\hline Kepuasan Mahasiswa(Y) & 295.33 & 582.449 & .769 & .766 & Reliabel \\
\hline
\end{tabular}

\section{Hasil dan Pembahasan}

\section{Karakteristik Responden}

Karakteristik demografi responden berdasarkan usia menunjukkan bahwa mahasiswa berusia 18 -20 tahun sebanyak 67,77\%. Pada usia ini, mahasiswa berada pada kondisi yang fresh graduated sebagai lulusan SMU/sederajat pada 1 sampai dengan 2 tahun terakhir. Sementara yang berusia 20 - 30 tahun sebanyak $31,11 \%$ sedangkan usia 30 tahun sebanyak $1,11 \%$. Pada usia ini, biasanya mahasiswa sudah terdaftar di perguruan tinggi lain/kuliah double, bahkan sudah bekerja sambil menempuh studi. Hal ini memberi arti bahwa sebagian besar responden adalah lulusan SMU/sederajat yang fresh graduated pada 1 sampai dengan 2 tahun terakhir.

Karakteristik demografi responden berdasarkan jenis kelamin menunjukkan bahwa perempuan sebanyak $61,12 \%$, sedangkan responden laki-laki sebanyak $38,88 \%$. Hal ini memberi arti bahwa 3 diantara 5 program pendidikan yang ditawarkan di Wearnes Education Center lebih banyak cocok dengan pekerjaan yang ditangani oleh wanita yaitu program pendidikan Ekspor Impor, Sekretaris dan Perpajakan karena menuntut ketelatenan dan ketelitian. Selain itu perkembangan jaman yang menuntut bahwa wanita mempunyai hak yang sama dalam berkarya di dunia kerja, sehingga semakin banyak wanita yang ingin memperdalam ilmunya dengan menempuh pendidikan singkat untuk dapat berkarir seperti halnya laki-laki.

Karakteristik demografi responden berdasarkan asal daerah menunjukkan bahwa mahasiswa berasal dari luar area Malang Raya yaitu sebanyak 65,55\% sedangkan 
responden di area Malang Raya sebanyak $34,44 \%$. Hal ini memberi arti bahwa mahasiswa lebih banyak berasal dari luar Malang Raya karena provinsi Jawa Timur yang tersebar di 38 kota/kabupaten di wilayah Jawa Timur dan ada pula yang berasal dari beberapa kota di luar Jawa Timur. Sedangkan sisanya area Malang Raya yang hanya tersebar di Kota Batu, Kota dan Kabupaten Malang.

Karakteristik responden berdasarkan jurusan/program studi yang diambil adalah jurusan Ekspor Impor sebanyak 36,66 \%, kemudian diikuti jurusan Sekretaris, Informatika, Perpajakan dan Desain Grafis yang paling sedikit sebanyak 7,77\%. Hal ini ini disebabkan biaya pendidikan jurusan Ekspor Impor yang termurah serta prospek kerjanya paling tinggi diantara jurusan lain. Sedangkan untuk jumlah peminat jurusan yang lain setiap tahun bervariasi jumlahnya tergantung pada trend permintaan pasar terhadap sumber daya manusia yang sedang booming dibutuhkan saat itu.

\section{Alat Analisa}

Dalam penelitian ini analisis regresi linear berganda digunakan untuk mengukur kualitas informasi SINKAD, kualitas sistem SINKAD, kualitas layanan akademik, kualitas layanan non akademik terhadap tingkat kepuasan mahasiswa Wearnes Education Center Malang Tahun Akademik 2017-2018.

Tabel 3. Hasil Analisis Regresi Linear Berganda

\begin{tabular}{|c|c|c|c|c|c|c|}
\hline \multicolumn{7}{|c|}{ Coefficients $^{a}$} \\
\hline \multirow[b]{2}{*}{ Model } & & \multicolumn{2}{|c|}{ Unstandardized Coefficients } & \multirow{2}{*}{$\begin{array}{c}\text { Standardized } \\
\text { Coefficients } \\
\text { Beta }\end{array}$} & \multirow[b]{2}{*}{$t$} & \multirow[b]{2}{*}{ Sig. } \\
\hline & & B & Std. Error & & & \\
\hline \multirow[t]{5}{*}{1} & (Constant) & -1.026 & 3.517 & & -.292 & .771 \\
\hline & Kualitas Informasi SINKAD & 288 & .076 & .342 & 3.797 & .000 \\
\hline & Kualitas Sistem SINKAD & .102 & .065 & .155 & 1.569 & .120 \\
\hline & Kualitas Layanan Akademik & .094 & .037 & .218 & 2.532 & .013 \\
\hline & $\begin{array}{l}\text { Kualitas Layanan Non } \\
\text { Akademik }\end{array}$ & .125 & .036 & .279 & 3.486 & .001 \\
\hline
\end{tabular}

Berdasarkan tabel tersebut dapat dirumuskan model persamaan regresi berganda sebagai berikut :

$$
Y=-1.026+0,288 X 1+0,102 \times 2+0,094 X 3+0,125 X 4+e
$$

\section{Pengujian Hipotesis}

Hipotesis yang ada dalam penelitian ini berjumlah lima, empat hipotesis pertama berkaitan dengan pengaruh secara parsial variabel kualitas SINKAD (terdiri kualitas informasi dan kualitas sistem) dan kualitas layanan (terdiri layanan akademik dan non-akademik) terhadap kepuasan melalui uji t, sedangkan hipotesis kelima adalah pengaruh secara simultan variabel tersebut terhadap kepuasan melalui uji F.

\section{Uji Signifikansi Parsial (Uji t)}

H1: Terdapat pengaruh kualitas informasi SINKAD terhadap kepuasan mahasiswa Nilai $t_{\text {hitung }}(3.797)>t_{\text {tabel }}(1.66298)$ dengan nilai signifikansi sebesar $0,000<0,10$, maka $\mathrm{H} 1$ diterima. Hasil hipotesa menunjukkan bahwa secara parsial terdapat pengaruh signifikan kualitas informasi (X1) terhadap kepuasan mahasiswa (Y).

H2: Terdapat pengaruh kualitas sistem SINKAD terhadap kepuasan mahasiswa 
Nilai $t_{\text {hitung }}(1.569)<t_{\text {tabel }}(1.66298)$ dengan nilai signifikansi sebesar 0,120 $>0,10$ maka $\mathrm{H} 2$ ditolak. Hasil hipotesa menunjukkan bahwa secara parsial tidak terdapat pengaruh signifikan kualitas sistem (X2) terhadap kepuasan mahasiswa (Y).

H3: Terdapat pengaruh kualitas layanan akademik terhadap kepuasan mahasiswa Nilai thitung $(2.532)>t_{\text {tabel }}(1.66298)$ dengan nilai signifikansi sebesar $0,002<0,10$, maka H3 diterima. Hasil hipotesa menunjukkan bahwa secara parsial terdapat pengaruh signifikan kualitas layanan akademik (X3) terhadap kepuasan mahasiswa (Y).

H4: Terdapat pengaruh kualitas layanan non-akademik terhadap kepuasan mahasiswa Nilai thitung $(3.486)>t_{\text {tabel }}(1.66298)$ dengan nilai signifikansi sebesar $0,001<0,10$, maka H4 diterima. Hasil hipotesa menunjukkan bahwa secara parsial terdapat pengaruh signifikan kualitas layanan non-akademik (X4) terhadap kepuasan mahasiswa (Y).

Dari hasil uji hipotesis dan analisa deskriptif, maka peneliti dapat membahas pengaruh antar variabel sebagai berikut :

\section{Pengaruh Kualitas Informasi SINKAD Terhadap Kepuasan}

Hasil penelitian ini menunjukkan bahwa kualitas informasi SINKAD memiliki pengaruh yang positif dan signifikan terhadap kepuasan mahasiswa. Berdasarkan dari hasil nilai ratarata distribusi frekuensi variabel kualitas informasi juga menunjukkan bahwa kepuasan mahasiswa berada pada level "Baik" pada kualitas informasi SINKAD. Makna dari hasil penelitian ini menunjukkan bukti secara empiris bahwa relevansi kualitas informasi SINKAD lebih dominan memberikan pengaruh terbentuknya kepuasan mahasiswa daripada keandalan informasi, keakuratan informasi, serta ketepatan waktu dalam menyajikan informasi. Penyebabnya adalah informasi yang disajikan dirasakan sangat bermanfaat bagi pengguna SINKAD karena menjelaskan kebutuhan mahasiswa sesuai jurusannya masingmasing yaitu menyajikan informasi nilai ujian, jumlah angsuran biaya pendidikan, jumlah ketidakhadiran perkuliahan berserta alasannya serta profil biodata dosen sehingga mudah dihubungi saat mahasiswa akan bimbingan tugas akhir. Akan tetapi kurang pada fungsi menambah wawasan bagi penggunanya, karena tidak adanya informasi tentang artikel yang dapat membantu menambah dan mendukung ilmu pada jurusan yang diambil, terutama perubahan UU Pajak yang baru pada jurusan Perpajakan.

Hasil penelitian ini mendukung teori yang dikemukakan oleh DeLone dan Mclean (1992) kualitas informasi adalah kualitas kemampuan konten dalam SINKAD dalam memberikan informasi yang disajikan apakah benar-benar dapat membantu mencari informasi yang dibutuhkan oleh penggunanya. Apabila informasi yang disajikan dalam konten SINKAD dirasakan sangat membantu dalam mencari informasi yang dibutuhkan maka pengguna informasi semakin puas.

Penelitian ini sejalan dengan penelitian Suaryana (2016) yang hasil penelitiannya menunjukkan bahwa kualitas informasi berpengaruh terhadap kepuasan pengguna sistem informasi berbasis web. Selain itu, juga mendukung penelitian Zeinab (2016) yang juga menunjukkan bahwa kualitas informasi Statistical Learning Toll memiliki pengaruh tidak langsung pada kinerja statistik melalui niat untuk menggunakan dan kepuasan pengguna.

\section{Pengaruh Kualitas Sistem SINKAD Terhadap Kepuasan}

Hasil penelitian ini menunjukkan bahwa kualitas sistem yang digunakan SINKAD tidak memiliki pengaruh signifikan terhadap kepuasan mahasiswa. Berdasarkan hasil nilai ratarata distribusi frekuensi variabel kualitas informasi menunjukkan bahwa kepuasan mahasiswa berada pada level "Baik" terhadap kualitas sistem SINKAD. Makna dari hasil penelitian ini menunjukkan bukti secara empiris bahwa sistem yang digunakan SINKAD 
tidak mempunyai pengaruh terbentuknya kepuasan mahasiswa. Hal ini dapat dianalisa bahwa sebagian besar pengguna memanfaatkan SINKAD hanya melalui local area network / intranet di lab komputer saja, padahal SINKAD juga dapat diakses melalui internet. Hal ini diasumsikan oleh pengguna bahwa sistem yang digunakan SINKAD kurang memuaskan, karena tidak dapat digunakan dimana saja pengguna berada. Selain itu respon waktu saat pengguna meng-upload foto foto kegiatan outing class membutuhkan waktu yang lama, petunjuk teknis cara pengoperasian SINKAD kurang dapat membantu pengguna, dan kapasitas SINKAD dalam menyimpan data berupa foto kegiatan outing class mahasiswa tidak sesuai kebutuhan mahasiswa. Hal-hal yang tersebut diatas, menyebabkan pengguna SINKAD merasa kurang puas dengan kualitas sistem yang digunakan SINKAD.

Selain itu, pengguna lebih menitikberatkan manfaat informasi yang disajikan daripada sistem yang digunakan. Pengguna sudah merasa puas bila informasi yang disajikan tersebut bermanfaat bagi studinya, mudah dijalankan tanpa mengalami hambatan yang berarti. Pengguna cenderung tidak memperhatikan jenis, merk, ukuran, spesifikasi hardware dan software apa yang digunakan SINKAD. Tidak adanya pengaruh sistem SINKAD terhadap kepuasan dapat juga disebabkan karena pengguna SINKAD kurang mengetahui secara detail, kriteria yang seperti apa suatu SINKAD itu disebut sebagai sistem yang berkualitas, karena cenderung tidak peduli hardware yang digunakan memakai merk apa, software menggunakan aplikasi apa, dan ukuran ram yang seberapa. Pengguna mengasumsikan bahwa selama SINKAD tersebut dapat dioperasikan dengan lancar tanpa mengalami suatu hambatan yang berarti, maka dapat dikatakan bahwa sistem yang digunakan SINKAD tersebut berkualitas.

Hasil penelitian ini berbeda dengan hasil penelitian Suaryana (2016), yang menyatakan bahwa kualitas sistem berpengaruh signifikan terhadap kepuasan pengguna sistem informasi berbasis web. Penelitian ini juga berbeda dengan penelitian Zeinab (2016) yang menunjukkan bahwa kualitas sistem Statistical Learning Toll memiliki pengaruh tidak langsung pada kinerja statistik melalui niat untuk menggunakan dan kepuasan pengguna.

\section{Pengaruh Kualitas Layanan Akademik Terhadap Kepuasan}

Hasil penelitian ini menunjukkan bahwa kualitas layanan akademik memiliki pengaruh yang positif dan signifikan terhadap kepuasan mahasiswa. Sedangkan hasil nilai rata-rata distribusi frekuensi variabel kualitas informasi menunjukkan bahwa kepuasan mahasiswa berada pada level "Sangat Baik" pada kualitas layanan akademik. Makna dari hasil penelitian ini menunjukkan bukti secara empiris bahwa keandalan kualitas layanan akademik lebih dominan memberikan pengaruh terbentuknya kepuasan mahasiswa daripada daya tanggap tenaga akademik dalam memberi layanan, kenyamanan fasilitas dan penampilan tenaga akademik , jaminan yang dipercaya dapat tenaga akademik memberikan layanan yang terbaik serta kepedulian tenaga akademik dalam memberikan layanan. Hal ini dapat dianalisa bahwa penyebab layanan tenaga akademik dapat diandalkan terutama karena kemampuan dosen dalam menguasai materi perkuliahan, dosen mampu mengoperasikan peralatan media pengajaran, menggunakan metode yang menarik dalam mengajar, teliti dalam mengoreksi, serta asdos mampu dalam menjalankan tugas asistensi di lab.

Hasil penelitian ini mendukung teori yang dikemukakan oleh Wyckop dalam Tjiptono (2000) bahwa kualitas jasa adalah tingkat keunggulan yang diharapkan dan pengendalian atas tingkat keunggulan tersebut untuk memenuhi keinginan konsumen. Selain itu diperkuat juga oleh teori oleh Kotler (1997) bahwa kualitas seringkali disamakan dengan mutu. Mutu sama dengan kualitas, dimana mutu adalah keseluruhan ciri dari atribut produk atau 
pelayanan yang berpengaruh pada kemampuannya untuk memuaskan kebutuhan yang dinyatakan atau yang tersirat". Hasil penelitian ini juga mendukung penelitian Izogo (2015), Agha (2016) yang menyatakan bahwa terdapat hubungan positif antara dimensi kualitas layanan yang terdiri dari tangible, emphaty, responsiveness, reliability, dan assurance dengan kepuasan konsumen. Selain itu, juga mendukung penelitian Mulyawan (2016) yang menunjukkan bahwa kualitas layanan yang terdiri dari 5 dimensi tersebut berpengaruh signifikan terhadap kepuasan mahasiswa.

Namun, penelitian ini berbeda dengan penelitian yang dilakukan oleh Jenniver (2016) karena secara simultan kelima dimensi berpengaruh signifikan terhadap kepuasan, namun secara partial hanya dimensi responsiveness saja yang memiliki pengaruh signifikan terhadap kepuasan mahasiswa.

\section{Pengaruh Kualitas Layanan Non-Akademik Terhadap Kepuasan}

Hasil penelitian ini menunjukkan bahwa kualitas layanan non-akademik memiliki pengaruh yang positif dan signifikan terhadap kepuasan mahasiswa. Sedangkan hasil nilai rata-rata distribusi frekuensi variabel kualitas informasi menunjukkan bahwa kepuasan mahasiswa berada pada level "Baik" pada kualitas layanan non-akademik. Makna dari hasil penelitian ini menunjukkan bukti secara empiris bahwa keandalan kualitas layanan nonakademik lebih dominan memberikan pengaruh terbentuknya kepuasan mahasiswa daripada daya tanggap tenaga non-akademik dalam memberi layanan, kenyamanan fasilitas non akademik, jaminan yang dipercaya dapat tenaga non-akademik memberikan layanan yang terbaik serta kepedulian tenaga non-akademik dalam memberikan layanan. Hal ini dapat dianalisa bahwa penyebab layanan tenaga akademik dapat diandalkan terutama karena kesiapan front office dan satpam menyambut mahasiswa sejak pertama kali datang, ketelitian front office dalam bekerja, kemampuan front office dalam mengoperasikan peralatan dan memberi solusi. Akan tetapi mahasiswa paling tidak puas dengan bukti fisik berupa lahan parkir yang kurang nyaman, tidak adanya fasilitas berupa kegiatan ekstrakurikuler untuk sekedar melepas lelah saat selesai kuliah serta sikap satpam dalam menawarkan bantuan yang seharusnya melayani dengan setulus hati bahkan melebihi apa yang diharapkan mahasiswa.

Hal ini didukung oleh teori yang dikemukakan oleh Hawkins dan Lonney (1997) bahwa atribut pembentuk kepuasan salah satunya adalah pelayanan oleh karyawan yang diperoleh sesuai atau melebihi dengan yang diharapkan serta fasilitas penunjang yang didapat sesuai atau melebihi dengan yang diharapkan. Hasil penelitian ini juga mendukung hasil penelitian Ali (2016) yang menyatakan bahwa aspek non akademik berdampak secara signifikan terhadap kepuasan mahasiswa.

\section{Kesimpulan}

Peningkatan kualitas (informasi dan sistem) SINKAD dan layanan (akademik dan non-akademik) merupakan upaya-upaya yang dilaksanakan oleh Wearnes Education Center Malang untuk membantu aktivitas mahasiswa dalam menempuh studi. Berdasarkan hasil pengujian hipotesis dan analisis deskriptif dari jawaban responden mengenai pengaruh kualitas SINKAD dan layanan terhadap kepuasan dapat ditarik kesimpulan sebagai berikut:

Relevansi informasi yang disajikan oleh SINKAD mempunyai pengaruh terhadap kepuasan mahasiswa di Wearnes Education Center Malang. Hal ini tercermin dari hasil penelitian bahwa penyajian informasi SINKAD dapat menjelaskan kebutuhan jurusan, memberikan manfaat dan menambah wawasan bagi mahasiswa dirasakan telah sesuai 
dengan harapan dan mampu menciptakan minat mahasiswa untuk merekomendasikan Wearnes Education Center Malang kepada orang lain.

Kualitas sistem SINKAD tidak mempengaruhi kepuasan mahasiswa di Wearnes Education Center Malang. Hal ini tercermin pada mahasiswa yang lebih banyak menggunakan SINKAD melalui local area network / intranet dan kurang memanfaatkan SINKAD melalui internet, sehingga pengguna mengasumsikan internet tidak dapat diakses di mana saja berada. Respon waktu saat upload foto outing class membutuhkan waktu lama, petunjuk teknis kurang dapat membantu pengguna, kemampuan SINKAD dalam menyimpan data berupa foto kegiatan outing class kapasitasnya tidak sesuai dengan yang dibutuhkan mahasiswa. Namun, meskipun terdapat kelemahan sistem SINKAD yang telah disebutkan diatas, spesifikasi hardware dan sistem software yang digunakan oleh SINKAD tersebut ternyata tidak berpengaruh terhadap kepuasan mahasiswa. Mahasiswa cenderung lebih memprioritaskan manfaat informasi yang dirasakan daripada memperhatikan jenis, merk dan spesifikasi hardware maupun software apa yang digunakan oleh SINKAD. Pengguna bahkan kurang mengetahui secara detail sistem yang seperti apa dapat dikatakan mempunyai kualitas sistem yang bagus. Begitu pengguna merasa mendapatkan manfaat dari informasi yang disajikan oleh SINKAD tanpa mengalami hambatan yang berarti, maka pengguna mengatakan puas terhadap sistem yang digunakan SINKAD. Kualitas sistem SINKAD tidak mempengaruhi terhadap tingkat kesesuaian dengan harapan dan minat pengguna untuk merekomendasikan pada orang lain.

Keandalan layanan akademik mempunyai pengaruh terhadap kepuasan mahasiswa di Wearnes Education Center Malang. Hal ini tercermin dari hasil penelitian bahwa kemampuan dosen dalam menggunakan metode yang menarik dalam mengajar, kemampuan dosen dalam menguasai materi kuliah, kemampuan dosen mengoperasikan peralatan sebagai media ajar, ketelitian dosen dalam mengoreksi hasil ujian serta kemampuan asdos dalam asistensi di lab. Layanan akademik dirasakan telah sesuai dengan harapan dan mampu menciptakan minat mahasiswa untuk merekomendasikan Wearnes Education Center Malang kepada orang lain.

Keandalan layanan non-akademik mempunyai pengaruh terhadap kepuasan mahasiswa di Wearnes Education Center Malang. Hal ini tercermin dari hasil penelitian bahwa kemampuan front office dalam memberi solusi, mengoperasikan peralatan, ketelitian dalam bekerja , kesiapan front office dan satpam melayani sejak pertama kali mahasiswa datang dirasakan telah sesuai dengan harapan dan mampu menciptakan minat mahasiswa untuk merekomendasikan Wearnes Education Center Malang kepada orang lain.

Kualitas informasi SINKAD, kualitas sistem SINKAD, kualitas layanan akademik dan kualitas layanan non-akademik secara bersama-sama mempunyai pengaruh terhadap kepuasan mahasiswa. Hal ini tercermin dari hasil penelitian bahwa penyajian informasi dan sistem yang digunakan oleh SINKAD, layanan akademik dan non-akademik dirasakan telah sesuai dengan harapan dan mampu menciptakan minat mahasiswa untuk merekomendasikan Wearnes Education Center Malang kepada orang lain.

Berdasarkan simpulan yang telah dilakukan dalam penelitian ini, maka saran bagi para peneliti selanjutnya diharapkan hasil studi ini dapat bermanfaat sebagai bahan acuan dengan menambahkan variabel lain agar dapat memberikan gambaran yang lebih luas mengenai faktor apa saja yang mempengaruhi kepuasan, menambahkan jumlah sampel agar memperoleh hasil yang lebih mendekati kondisi sebenarnya, melakukan penelitian dengan obyek yang berbeda di beberapa daerah (Bali dan Madiun) agar dapat menentukan strategi perusahaan di masa yang akan datang, serta melakukan penelitian pada responden 
yang berbeda (orang tua mahasiswa) agar diketahui faktor-faktor yang dapat menentukan kepuasan.

\section{Daftar Pustaka}

Ali Faizan et.al,. 2016. Does Higher Education Service Quality Effect Student Satisfaction, Image and Loyalty : A Study of International Students in Malaysian Public Universities, Vol 2 (1) : 70-94

Arikunto, S. 2006. Prosedur Penelitian Suatu Pendekatan Praktik Edisi Revisi VI. Jakarta. Rineka Cipta.p.136

DeLone, W.H., McLean, E.R. 1992. Information Systems Success: The Quest for The Dependent Variable. Information System Research Vol 3 (1): 60-95.

Hawkins. 1997. Consumer Behaviour: Building Marketing Strategy. McGraw-Hill. USA

Ismatullah. 2014. Analisis Penerapan Sistem Informasi Akademik (Siakad) Online di Universitas Sultan Ageng Tirtayasa, p. 36

Izogo Emeka Ernest et. al. 2015. Service Quality, Customer Satisfaction and Loyalty in :Automobile Repair Services Sector, International Journal of Quality \& Reliability Management, Vol. 32(3):250 - 269.

Jenniver Vinny et.al, .2016. Pengaruh Kualitas Pelayanan Akademik Terhadap Kepuasan Mahasiswa : Studi pada mahasiswa Administrasi Bisnis Universitas Telkom Bandung , Vol 2 (2) : 125-133Jogiyanto H.M.1999. Analisis dan Disain Informasi: Pendekatan Terstruktur Teori dan Praktek Aplikasi Bisnis, Andi Offset.Yogyakarta . p. 11.

Kasiri Leila Agha et. al,. 2016. Integration of Standardization and Customization: Impact on Service Quality, Customer Satisfaction, and Loyalty, Vol 35 : 91-97

Kotler, Philip.1997. Manajemen Pemasaran : Analisis perencanaan Implementasi dan Kontrol, Jilid I Dan Jilid II, PT Prenhalindo. Jakarta.p.49-263

Kotler, Philip, and Kevin Lane Keller. 2012. Marketing Management, Fourteenth Edition Essex. Pearson Education Limited. England.p.150.

Moenir, HAS. 2001. Manajemen Pelayanan Umum di Indonesia, Bumi Aksara, Edisi V, Jakarta . p. 27.

Mulyawan A. et.al,. 2016. Pengaruh Kualitas Layanan Akademik Terhadap Kepuasan Mahasiswa Serta Implikasinya pada Loyalitas Mahasiswa :Studi Pada Sekolah Tinggi Manajemen Informatika dan Komputer di Kota Bandung, Vol 10 (2) : 119131Mustakini dan Jogiyanto Hartono. 2009.Sistem Informasi Teknologi, Andi Offset, Yogyakarta . p. 34

MTebe Joel et.al, . 2018. Key factors in learners' satisfaction with the e-learning system at the University of Dar es Salaam, Tanzania, Australasian Journal of Educational Technology. Vol 34(4): 107-122.

Oktavia Dwi Dayanti et.al, . 2016. Faktor-Faktor yang Mempengaruhi Kesuksesan Sistem Informasi Manajemen Daerah dengan Pendekatan Model DeLone dan McLean yang Dimodifikasi. Tesis, Universitas Brawijaya, Malang.

Olgun Kitapei et.al,. 2014. The Impact of Service Quality Dimensions on Patient Satisfaction, Repurchase Intentions and Word-of-Mouth Communication in the Public Healthcare Industry, Vol. 148:161-169

Parasuraman, A., Berry, Leonard L, and Zeithaml, Valarie A. 1991. Refinement and Reassessment of The SERVQUAL Scale, Journal of Retailing, Vol 67 (4) : 420-450. 
Sing, J. 1988. Customer Complaint Intentions and Behaviour, Journal of Marketing, Vol 52 (1): $93-107$

Suaryana I Gusti Ngurah Agung et.al. 2016. Kualitas dan Kepuasan Pengguna terhadap Sistem Informasi Akademik Berbasis Web, Jurnal IImiah Akuntansi dan Bisnis, Vol. $11(2): 84-90$.

Tjiptono, Fandy. 2000. Manajemen Jasa, Edisi Kedua, Andy Offset, Jakarta.p.49

Zaremohzzabieh Zeinab et. al ,. 2016. A Model of Information Systems Success for Assessing the Effectiveness of Statistical Learning Tool on University Students Performance in Statistics, Vol 7 (2) : 271-281 